\title{
O VOO LIVRE COMO CONTEÚDO DA EDUCAÇÃO FÍSICA NA EDUCAÇÃO INFANTIL: DESCOBERTAS E DESAFIOS
}

\author{
Juliana Silva Santiago ${ }^{1}$, Luísa Lenhardt ${ }^{2}$, José Ricardo Silva ${ }^{3}$, Fabio Machado Pinto ${ }^{4}$ \\ ${ }^{1}$ Graduanda em Educação Física na Universidade Federal de Santa Catarina - UFSC. E-mail: \\ juliana santiago06@hotmail.com \\ ${ }^{2}$ Graduanda em Educação Física na Universidade Federal de Santa Catarina - UFSC. E-mail: luisa.lenhardt@gmail.com \\ ${ }^{3}$ Doutor em Educação pela Universidade Estadual Paulista - UNESP, Presidente Prudente. Docente de Educação Física \\ do Ensino Básico, Técnico e Tecnológico no Núcleo de Desenvolvimento Infantil (NDI) da Universidade Federal de \\ Santa Catarina - UFSC, Florianópolis. E-mail: ricardosilvaunesp@gmail.com \\ ${ }^{4}$ Doutor em Sciences de Léducation - Université de Paris 8. Docente do Centro de Educação da Universidade Federal \\ de Santa Catarina - UFSC, Florianópolis. E-mail: fabiobage@gmail.com
}

\section{RESUMO}

Este artigo relata e reflete sobre o ensino do voo livre nas aulas de Educação Física na Educação Infantil. Tomamos esta prática corporal como objeto de ensino em articulação com o conteúdo literário explorado pela professora do grupo e por haver na cidade intensa prática de esportes de aventura e, dentre elas, o voo livre. Assim, objetivamos proporcionar um conhecimento sistematizado sobre este conteúdo pouco explorado pela Educação Física, relacionar o voo livre às experiências corporais como o equilíbrio, a corrida, o salto, o sentimento de medo e os equipamentos de segurança. As atividades ocorreram em uma instituição de Educação Infantil vinculada a uma universidade federal no contexto do estágio em Educação Física escolar. Participaram diretamente deste experimento de ensino 17 crianças com faixa etária entre 5 e 6 anos de idade, a professora da turma, uma auxiliar de creche, uma estagiária do curso de Pedagogia, um professor de Educação Física e 2 estagiárias do curso de Educação Física. Como resultado destacamos que esta experiência de ensino proporcionou às crianças a capacidade de identificação e diferenciação entre asa delta e o parapente enquanto experimentavam situações de equilíbrio/desequilíbrio em lugares altos e baixos, construíam brinquedos, brincavam e estabeleciam contato com equipamentos reais. Os sentimentos de vertigem, medo, confiança, alegria e segurança foram experimentados e objetos de reflexão juntos às crianças no sentido de conhecê-los, nomeá-los e superá-los. Por fim, salientamos a importância da formação docente, o planejamento e ensino de práticas de aventura, assim como melhor conhecer os sujeitos deste processo.

Palavras - chave: Esportes de aventura. Voo livre. Educação Física. Educação Infantil. Estágio Supervisionado.

\section{FREE FLIGHT AS CONTENT OF PHYSICAL EDUCATION IN EARLY CHILDHOOD EDUCATION: DISCOVERIES AND CHALLENGES}

\section{ABSTRACT}

This article reports and reflects on the teaching of hang gliding in Physical Education classes in kindergarten. We take this body practice as an object of teaching in articulation with the literary content explored by the group's teacher and the intense practice of adventure sports in the city, including free flight. Thus, we aim to provide a systematized knowledge about this content little explored by Physical Education, relating free flight to body experiences such as balance, running, jumping, fear and safety equipment. The activities took place in a kindergarten institution linked to a federal university in the context of the school Physical Education internship. Seventeen children between the ages of 5 and 6 years old participated directly in this teaching experiment, the class teacher, a daycare assistant, a pedagogy intern, a physical education teacher and 2 physical education interns. As a result we highlight that this teaching experience provided the children with the ability to identify and differentiate between paragliding 
hang gliding while experiencing balance / imbalance situations in high and low places, building toys, playing games and making contact with real equipment. The feelings of vertigo, fear, confidence, joy and security were experienced and objects of reflection together with the children in order to know, name and overcome them. Finally, we emphasize the importance of teacher education, the planning and teaching of adventure practices, as well as better knowing the subjects of this process.

Keywords: Adventure sports. Free fly. PE. Child education. Supervised internship.

\section{VUELO LIBRE COMO CONTENIDO DE LA EDUCACIÓN FÍSICA EN LA EDUCACIÓN INFANTIL: DESCUBRIMIENTOS Y DESAFÍOS}

\section{RESUMEN}

Este artículo informa y reflexiona sobre la enseñanza del ala delta en las clases de educación física en el jardín de infantes. Tomamos esta práctica corporal como un objeto de enseñanza en articulación con el contenido literario explorado por el maestro del grupo y la práctica intensa de deportes de aventura en la ciudad, incluido el vuelo libre. Por lo tanto, nuestro objetivo es proporcionar un conocimiento sistematizado sobre este contenido poco explorado por la Educación Física, que relaciona las experiencias de vuelo libre con el cuerpo, como el equilibrio, la carrera, el salto, el miedo y el equipo de seguridad. Las actividades tuvieron lugar en una institución de jardín de infantes vinculada a una universidad federal en el contexto de la pasantía de Educación Física de la escuela. Diecisiete niños entre las edades de 5 y 6 años participaron directamente en este experimento de enseñanza, el maestro de clase, un asistente de guardería, un interno de pedagogía, un maestro de educación física y 2 pasantes de educación física. Como resultado, destacamos que esta experiencia de enseñanza proporcionó a los niños la capacidad de identificar y diferenciar entre ala delta parapente mientras experimentaban situaciones de equilibrio / desequilibrio en lugares altos y bajos, construyendo juguetes, jugando y haciendo contacto con equipos reales. Se experimentaron los sentimientos de vértigo, miedo, confianza, alegría y seguridad y objetos de reflexión junto con los niños para conocerlos, nombrarlos y superarlos. Finalmente, enfatizamos la importancia de la formación del profesorado, la planificación y enseñanza de prácticas de aventura, así como un mejor conocimiento de los temas de este proceso.

Palabras clave: Deportes de aventura. Vuelo libre. Educación Física. Educación Infantil. Prácticas supervisadas.

\section{INTRODUÇÃO}

Inicialmente, é preciso esclarecer que situamos as práticas corporais e esportes de aventura a partir da conceituação de Pereira e Armbrust (2010), quando caracteriza o esporte em seus aspectos de rendimento, participação e lazer e, complementarmente, aventura, por seus aspectos de risco, situações que proporcionam a sensação de medo haja vista a imprevisibilidade e o 'campo' desconhecido para o seu praticante. Tais autores acreditam que vivenciar os esportes de aventura contribui para a formação humana, pois possibilitam a relação, o respeito e o cuidado entre os pares e o contato e valorização dos espaços naturais. Neste sentido, estamos convencidos de que as práticas corporais e os esportes radicais são conhecimentos históricos humanos que precisam ser abordados didaticamente na escola via Educação Física.
Contudo, Paixão (2017), aponta para a difícil tarefa de rompermos com paradigmas que cristalizaram os esportes coletivos como representantes da Educação Física escolar. Acrescentamos, ainda, que este movimento de inserção de esportes de aventura distancia-se ainda mais da realidade escolar quando tratamos da Educação Infantil. Portanto, faz-se necessário que nós, professores de Educação Física, tomemos este conteúdo da mesma forma que os outros esportes ou os outros conteúdos pertinentes à área em toda a Educação Básica. É na busca de superação destes paradigmas que marcam a Educação Física que apresentamos este relato de experiência.

No bojo desta discussão este texto pretende relatar uma experiência de ensino das práticas corporais de aventura, de uma modalidade de esporte radical, o voo livre, em uma instituição de Educação Infantil, mais 
especificamente, com crianças entre cinco e seis anos de idade. $O$ contexto deste trabalho se deu na modalidade de estágio supervisionado do curso de licenciatura em Educação Física da Universidade Federal de Santa Catarina (UFSC), Florianópolis, em uma instituição de Educação Infantil federal ao longo do primeiro semestre de 2019. Esta experiência foi realizada de forma supervisionada pelo professor de Educação Física das duas instituições envolvidas.

Vale salientar que este tema, o voo livre, não foi selecionado sem qualquer critério. Durante as nossas primeiras aproximações com o grupo de crianças e adultos da sala (uma professora e uma auxiliar de sala), observamos que semanalmente um capítulo de um livro era apresentado às crianças. O livro a que nos referimos era 'As Aventuras do Barão de Munchausen'. A professora contou às crianças que, em algumas de suas aventuras, o 'Barão' consegue alçar voos. Aliado a esta aproximação à literatura, consideramos que o voo livre seria o conteúdo a ser proposto, também, pelo fato de que na cidade de Florianópolis, há a prática de diferentes modalidades de voo livre pelos residentes e turistas. Foi a partir destes indicativos que optamos por esta modalidade.

As propostas realizadas seguiram um modelo expositivo de imagens e vídeos, propositiva de experiências corporais que se relacionavam com a modalidade discutida e dialogada em diferentes momentos. As atividades de corpo e movimento proporcionaram vivências de equilíbrio, de corrida, de salto e voo, bem como os sentimentos de medo, vertigem, (in)segurança, construção de brinquedos e experimentação de equipamentos de segurança e da própria asa delta. Os diálogos foram valorizados em todos os momentos: no início e ao longo de todas as atividades e nas rodas de conversa para a avaliação da proposta e diálogo sobre as próximas.

Assim, este artigo objetiva relatar a experiência de ensino da modalidade voo livre enquanto conteúdo da Educação Física na Educação Infantil. Acreditamos que o relato que segue, poderá auxiliar e contribuir para a reflexão e ação no ensino de esportes de aventura, sobretudo o voo livre, pelos professores de Educação Física atuantes na Educação Infantil.

\section{Campo de voo: a instituição de Educação Infantil e as crianças}

A aproximação e tomada de conhecimento da instituição em que realizamos o estágio se utilizou de estratégias etnográficas como as observações dos momentos de Educação Física e da rotina organizada e proposta pela professora responsável pelo grupo, por exemplo, nos momentos de lanche e parque. Além das observações, realizamos entrevista com o professor de Educação Física e análise dos documentos da instituição. (VAZ; SAYÃO; PINTO, 2002).

A unidade atende crianças de zero a cinco anos e onze meses e o ingresso se dá através de sorteio aberto a comunidade. É um núcleo de referência no âmbito da Educação Infantil, situado dentro da UFSC. Mantém atividades de ensino, pesquisa e extensão articuladas com a Universidade. Conta com vinte e três professores, sendo quatro substitutos, equipe composta por auxiliares de creches, estagiários, enfermeiras e técnica de enfermagem, nutricionistas, técnicos administrativos, cozinheira, mestre de ofício e técnica em assuntos educacionais.

A instituição possui instalações diversas. São parques, sala de desafios corporais, quadra poliesportiva, área verde com árvores e arbustos, canteiros, horta, auditório, biblioteca entre outros espaços interessantes para realização das atividades. Há também salas com diferentes matérias lúdicos e de apoio para as mais diversas atividades. Na sala de materiais de Educação Física pode-se encontrar: colchões, colchonetes, bolas, arcos, cordas, equipamentos de segurança, bastões, brinquedos, tábuas de madeira e outros. Além desta configuração, é comum as professoras e turmas explorarem áreas externas no entorno.

A Proposta Curricular em vigor foi elaborada em 2014, através de intenso trabalho coletivo. Este documento segue as normativas legais da Educação Brasileira e aportes da teoria histórico-cultural, tendo como principal precursor, o psicólogo russo Vigotsky. De acordo com o documento:

No interior deste aporte teórico no campo da psicologia do desenvolvimento, a periodização da ontogênese humana traz importantes contribuições

\footnotetext{
${ }^{1}$ Autoria de Rudolf Erich Raspe, 1785
} 
para a compreensão das crianças pequenas, indicando as especificidades das atividades pedagógicas a serem contempladas no currículo da educação infantil. (PROPOSTA CURRICULAR NDI, 2014, p. 26)

Nesta proposta a criança é concebida como um sujeito histórico e de direitos que se desenvolve partir da aprendizagem num determinado meio social e por meio de sua atividade principal: o brincar.

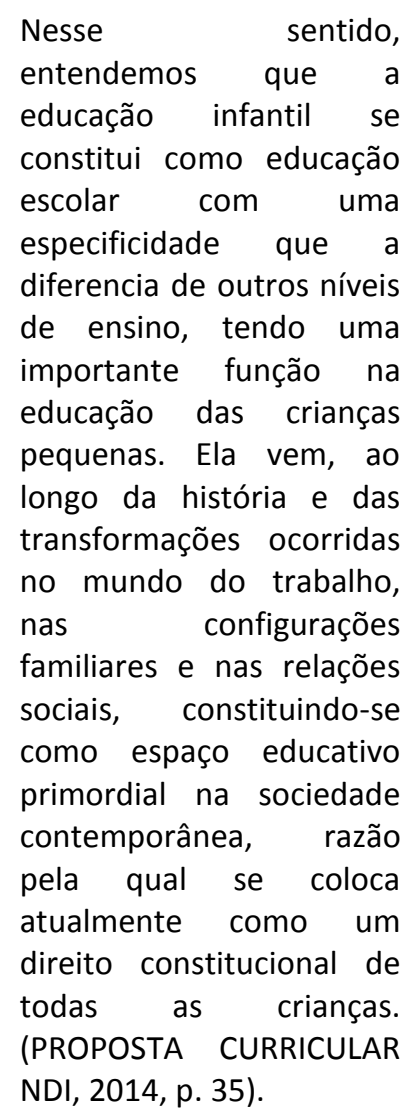

A partir destes indicativos, nossa atuação na instituição buscou considerar a brincadeira como eixo principal de nossas ações, ou seja, em nossos planejamentos, organização do tempo, espaço e materiais utilizados, levou a cabo a imaginação no contexto do faz de conta. Além disso, assumimos, sob a supervisão dos professores responsáveis, a função de ensinar as crianças sobre o voo livre no contexto da Educação Infantil.

O grupo de crianças que participaram desta experiência de estágio, o grupo 6 (G6), é composto por crianças de cinco a cinco anos e onze meses, são dez meninos e sete meninas. Esse grupo frequenta a instituição no período matutino. Os adultos que compõem o grupo são uma professora efetiva, uma auxiliar de creche efetiva e uma estagiária do curso de Pedagogia. Há três adultos atuando neste grupo devido à presença de uma criança do público alvo da Educação Especial. Esta criança apresenta laudo de alto grau de autismo, observamos que costuma ficar próxima das atividades das que as crianças realizam, observa seus colegas, poucas vezes interage e isso fica evidente nas aulas de EF e, também, nas intervenções do estágio. Outra criança nos chamou atenção durante as observações iniciais, pois protagonizou diversos episódios de agressividade com os pares e adultos da turma. Tomamos conhecimento de que esta criança está sendo acompanhada pelos profissionais da instituição e, após encaminhamentos em comunhão com a família, frequenta outras instituições de auxílio psicológico e pedagógico. Estas duas crianças mobilizaram todos os adultos envolvidos para melhor atender as expectativas em torno de nossas ações. As observações e as conversas ofereceram importantes elementos para o planejamento e organização dos momentos de Educação Física.

Desde o início o grupo se mostrou participativo, tanto os momentos dialogados em sala ou na exibição de vídeos e imagens no auditório. É verdade que as crianças da educação infantil demonstram agitação e interesse em expressar suas opiniões, vontades e descontentamentos. É um grupo que gosta de movimentar-se, de sair da sala e responder às perguntas com sinceridade, por exemplo: "eu não gostei de nenhuma atividade". Esta fala se deu durante uma roda de conversa realizada no final da aula de EF. Observamos que a relação entre crianças e professores é de muito diálogo.

A organização do tempo na unidade busca respeitar, na medida do possível, os interesses das crianças. Os horários são mais flexíveis para as diversas atividades e alimentação. Os horários das aulas de EF são agendados e combinados com antecedência pelos professores responsáveis. Nesta perspectiva, os professores buscam trabalhar em conjunto, um planejamento articulado entre as propostas. Os conteúdos da EF na perspectiva do professor EF são: jogos, danças, ginásticas, esportes, lutas, dentre outros. 


\section{1 - As observações nas aulas de Educação Física: uma visão panorâmica}

Observamos, registramos e refletimos um conjunto de três aulas, sendo duas em sala e uma de EF. Durante as observações o clima encontrava-se estável, variando um pouco a temperatura, mas nada que interferisse diretamente nas aulas. A EF não possui um dia semanal definido para ocorrer, depende do acordo entre professores. A proposta da EF encontra-se em reformulação visto que é o primeiro ano do professor efetivo e este ainda está se adaptando a realidade e especificidades da Educação Infantil. Contudo, sua visão de EF e infância mantém certa coerência com aquela anunciada pela unidade, em que a visão de criança valoriza suas experiências e histórias. Eles oferecem liberdade e autonomia para as crianças explorarem os espaços da unidade, visto que, por vezes, saem da sala e retornam seja para beberem água, irem ao banheiro ou buscar algum material de interesse. Vale ressaltar que esta movimentação, embora aparentemente livre, ocorre sob a observação de todos os adultos que circulam e atuam na instituição fortalecendo o vínculo entre todos os presentes. Observamos que com o professor de EF elas ficavam animadas, mas quando ocorria um problema recorriam à professora. Em determinadas situações apenas ela conseguia apaziguar os ânimos. $^{2}$

Na observação da aula de EF chegamos em sala junto com o professor. As crianças encontravam-se agitadas e a professora de sala precisou interferir para que elas se sentassem e se acalmassem para escutar a proposta do professor. Este então explicou o que iria acontecer e fez um breve alongamento de forma lúdica. Posteriormente, em nossa conversa, ele comentou que acha esse momento importante para promover a concentração das crianças e para que elas iniciem uma relação com a prática e importância de alongamentos. Em seguida, apresentou as estagiárias de EF e perguntou se poderíamos brincar com eles. Saindo da sala em direção ao pátio, o professor formou um trenzinho e entoou cantigas para organizar $o$ deslocamento. Neste momento, todos os adultos do G6 acompanham o grupo. Ao todo

\footnotetext{
${ }^{2}$ Vale destacar que este é o primeiro semestre do professor de EF no Núcleo, efetivado por um concurso recente que inaugurou uma nova fase com um profissional da área, contratado especificamente para as aulas de EF.
}

contávamos seis adultos para um grupo de 15 crianças.

$\mathrm{Na}$ atividade proposta, o pega-pega, um grupo representava os leões e o outro os jacarés, personagens que derivam da história que a professora de sala estava trabalhando com o grupo: as aventuras do "Barão". Além de pegar os colegas, teriam que levá-los a uma casinha e impedir que fugissem. Essa brincadeira teve uma boa adesão e interesse da turma. Quando o professor percebeu que as crianças estavam perdendo o interesse, prosseguiu propondo outro desafio corporal vinculado à história: "bola de fogo". O professor organizou as crianças em roda e mostrou uma corda com uma bola na ponta que ao girá-la, as crianças deveriam pular ou abaixar mediante a altura do brinquedo. Algumas crianças tiveram dificuldade, mas o professor as incentivava a continuar na brincadeira, se utilizando da comunicação, dizendo: - "cuidado se não vai queimar o cabelo de vocês." "Ah! Vocês se queimaram pulem mais alto na próxima vez." Finalmente, a atividade final, que foi denominada "arco de fogo". Nesta o professor comandava a atividade. As crianças tinham que pular por dentro do arco em diferentes alturas. Após sinalizarem a estafa, as crianças foram conduzidas até uma área coberta, assim ele pediu que deitassem, fechassem os olhos e prestassem a atenção na sua respiração. Depois, solicitou que se sentassem e falassem o que houve na aula e o que eles mais gostaram, ligando as atividades aos acontecimentos da história contada pela professora. Neste momento, a professora da sala interviu para ampliar a compreensão das crianças.

Numa outra observação, em sala, presenciamos uma contação de história sobre "As aventuras do Barão de Munchausen". As crianças sentaram-se em roda para escutar a história. Ocorreram alguns conflitos entre as crianças que foram mediados pelos adultos presentes. A professora prosseguiu contando a história até o seu final.

Percebemos nas observações que as aulas de EF e os eventos realizados na turma valorizam a cultura infantil, enriquecendo com histórias divertidas, trabalhando sempre com elementos do mundo imaginário da criança e propondo interação social e afetiva entre elas e os adultos. É evidente o esforço interdisciplinar entre os profissionais. A contação de histórias, a construção de brinquedos para serem utilizados 
nas aulas e leva-los para casa, entre outras estratégias contribuem na educação das crianças.

Ao longo de nossas observações e diálogos com os adultos que nos supervisionavam, tomamos conhecimento de que, para este grupo, precisávamos cuidar do tempo de espera durante e entre as atividades propostas. A experiência destes profissionais, especificamente com o G6, nos indicou este caminho para as nossas intervenções: evitar o tempo em que as crianças ficam em filas ou sentadas esperando a oportunidade de vivenciar a proposta, momento propício para gerar agressividade.

\section{O voo livre na Educação Infantil: os preparativos}

Como anunciado anteriormente, a escolha do voo livre teve relação com o livro utilizado pela professora do $\mathrm{G} 6$ e com as práticas corporais de aventura realizadas na cidade de Florianópolis. Neste sentido, nosso objetivo geral se estruturou em torno do conteúdo, partindo do princípio de que na história a questão de voo e voar apareceram com frequência, quando o Barão se utiliza do Balão para fugir de perigos e construir Parapentes. Considerando a relação das crianças com a natureza, apresentamos elementos da cultura do Voo livre, buscando refletir como o homem aprendeu a voar e suas formas de realizar.

Esse encontro de interesses nos levou a refletir, planejar, organizar o tempo, o espaço e materiais que proporcionassem às crianças aproximação aos conceitos das modalidades de voo livre e os sentimentos característicos dos esportes de aventura, os perigos e emoções enfrentados pelo personagem junto à natureza. Tal como aponta a Base Nacional Curricular Comum (BNCC) sobre os esportes de aventura "Criar com o corpo formas diversificadas de expressão de sentimentos, sensações e emoções; reconhecer regra de segurança e de coletividade" (BRASIL, 2018).

Esta escolha consistiu num grande desafio, visto que o tema é raro nas aulas de EF e na Educação Infantil. Na EF, seja na proposta do Município de Florianópolis (2016) quanto na BNCC (2018) este conteúdo integra o conteúdo das Práticas Corporais de Aventura na Natureza (PCANs) e consiste em uma experiência de voo com equipamentos sem utilização do motor. $O$ que move os equipamentos são as correntes de $\operatorname{ar}$ (KOCK, 2007).
As propostas de Educação Física contidas na BNCC (2018) e na Proposta do Munícipio de Florianópolis (2016) fazem parte dos fundamentos teórico-metodológicos de nosso trabalho. Neles temos a importância de uma Educação Física que promova vivências diversificadas e a interdisciplinaridade com os outros componentes da área das linguagens (arte, língua portuguesa e língua estrangeira). Com relação à Educação Infantil, a BNCC propõe vivências e atividades relacionadas à identificação de cores, formas, espaços, proporcionando relações e trazendo elementos para que elas possam se conhecer, participar, expressar e explorar o ambiente (BRASIL, 2018).

Ao tematizar a Cultura Corporal de Movimento, buscamos dar ênfase as Práticas Corporais de Aventuras na Natureza (PCAN), para promover vivências e reflexões sobre seus sentidos e significados. Buscamos tematizar os conteúdos, a fim de que o aluno despertasse para elementos da sua realidade, para aguçar sua curiosidade sobre as dimensões técnicas, conceituais, éticas e estéticas do conhecimento. (FLORIANÓPOLIS, 2016, p. 142). Neste sentido, perspectivamos uma EF que proporcionasse uma formação humana, relacionada às questões contemporâneas da realidade de cada criança, valorizando suas experiências. Trata-se de ampliar as possibilidades curriculares, tendo como centralidade o conhecimento sistematizado e de acordo com os seguintes princípios: a sua relevância social, a contemporaneidade, a adequação às possibilidades sócio cognoscitivas do aluno, a simultaneidade dos conteúdos enquanto dados da realidade, a espiralidade da incorporação das referências do pensamento e a provisoriedade do conhecimento (SOARES et al, 1992).

As aulas foram organizadas sistematicamente em três momentos: introdução do tema, desenvolvimento das atividades e avaliação/reflexão sobre as experiências realizadas. Cada conversa com as crianças buscava despertar o interesse pelo tema, que se reconhecessem como sujeitos das experiências e avaliar aspectos significativos das aulas. Durante estas atividades nos utilizamos de recursos diversos como fotos, filmagens, gravações que permitiram em alguns momentos construir a experiência e proporcionar um momento de reflexão junto aos alunos.

Os espaços utilizados para as aulas foram a sala de aula, os parques dentro da instituição e 
espaços verdes fora dela e, também, locais cobertos, pois tivemos dias de chuvas que exigiram uma adaptação das aulas. Utilizamos também o auditório. Os materiais utilizados foram as cordas, capacetes, colchonetes, equipamentos de tirolesa e segurança, slackline, parede de escalada entre outros. E os materiais que construímos ou levamos para as crianças foram, cartolinas com imagens de voo livre, mini parapentes, pipas, parapentes de plástico, lona e tecidos. E, por último, uma asa delta oficial.

\section{Experiência de ensino do voo livre}

Organizamos o módulo de ensino em cinco aulas, sendo uma aula semanal com duração de aproximadamente $2 \mathrm{~h}$ e 30 minutos, com intervalo para lanche. Estas aulas foram planejadas e discutidas com os professores da disciplina de estágio supervisionado do curso de licenciatura em EF. A cada encontro registramos, avaliamos as aulas realizadas e reorganizamos a continuidade dos trabalhos.

A primeira intervenção se deu a partir de uma conversa que aconteceu no auditório da instituição, onde nos apresentamos e explicamos o nosso plano às crianças. Em seguida, colocamos colchonetes para criar uma atmosfera mais confortável e apresentamos alguns vídeos e imagens de esportes de aventura que são realizados na cidade. Conversamos e apresentamos exemplos de PCAN e depois, mais especificamente, o voo livre. Algumas crianças ficaram com medo e disseram que: "não iriam fazer aquilo". Então, explicamos que não era nossa intenção fazê-los voar daquela maneira. Mas que gostaríamos de mostrar algumas brincadeiras que tinham relação com aquelas atividades e que um dia, se desejassem, poderiam aprender a voar daquela forma. Enfatizamos que para voar é necessário aprender a correr, equilibrar, saltar.

Nessa aula o professor de EF e a professora de sala ajudaram bastante, relacionando a nossa prática a história que eles estavam vendo e perguntando o que eles já conheciam, o que já tinham feito de práticas na natureza. Com ajuda do professor colocamos os colchonetes juntos e pedimos para que elas pulassem do palco do auditório em cima, iniciando assim nossa temática com eles. No final dessa aula conversamos sobre o próximo encontro e nos despedimos.

A segunda intervenção teve início na sala do G6. Em roda, apresentamos imagens para discutir conceitualmente as diferenças entre o parapente e a asa delta. Sentamos em roda com as crianças e perguntamos sobre as imagens. $\mathrm{Na}$ medida em que respondiam, colávamos figuras numa cartolina de modo a agrupar aquelas que se referiam a esta ou aquela modalidade. Questionamos e conversamos com as crianças acerca das diferenças entre os equipamentos de segurança, peso e medida dos aparelhos, tempo de voo, relação com o vento, com o local de onde se salta e os riscos. As crianças mostraram-se muito interessadas e participativas. Em seguida, as crianças receberam a visita de um estagiário que se fantasiou de Barão de Munchaussen e contou um pouco mais de suas aventuras de voos. Em seguida, conduzimos as crianças para uma área onde montamos previamente uma tirolesa para as crianças vivenciarem situações de altura, vertigem e conhecerem alguns equipamentos (cinto e capacete). Para evitar o tempo ocioso de espera, organizamos atividades de equilíbrio em um slackline e o Barão continuava a conversar com as crianças. Esta situação não evitou os conflitos entre as crianças. Entendemos que seria necessário oferecer mais às crianças! A criança autista não deixou que colocássemos os equipamentos de segurança, mas acompanhou o voo dos colegas e junto da auxiliar acabou entrando no circuito de equilíbrio.

Um acontecimento chamou nossa atenção nesta aula. Uma aluna subiu para fazer a tirolesa, porém estava com muito medo. Ela não conseguia soltar as mãos do cabo, e se mostrava tensa. Conseguimos explicar para ela que estava segura, que existia uma corda que a prendia. Depois demos as mãos para ela segurar. Ainda assim, ela demonstrava muito medo, mas conseguiu relaxar e a levamos até uma ponta da tirolesa, quando estávamos chegando ao fim da tirolesa ela estava sorrindo e dizendo que queria ir de novo. Este episódio possibilitou que fizéssemos uma conversa com as crianças sobre os sentimentos, dando nomes a eles. Conversar e identificar uma situação de medo é importante como forma de enfrentar e superar situações que causam medo e pavor. Um tema importante para a Educação Física escolar. Também tivemos outro aluno que disse que voar desse jeito era coisa de louco. Quando estava na fila para ir à tirolesa perguntamos se ele gostaria de ir, mas este não arriscou. No auditório usamos sacos de lixos abertos como parapentes e eles pularam do palco, para experimentar a sensação de voar. Elas gostaram, mas no final da aula notamos que 
estavam agitadas. Por fim, as crianças ficaram brincando com o parapente no corredor do G6.

A terceira intervenção começou em sala. As crianças estavam calmas sentadas ouvindo trechos da história que a professora de sala contava. A estagiária começou a aula contando que o Barão deixou um bilhete para ela e que continha desafios a serem realizados, para no fim elas ganharem um tesouro que o mesmo deixara. Então, relembrou a aula passada, na qual as crianças participaram bastante, explicou que para eles irem ao local dos desafios deveriam se dirigir imitando animais que mais gostavam. Chegando à quadra o professor e a estagiária propuseram um alongamento lúdico e explicaram também o porquê desta atividade para os pilotos de voo livre. Posteriormente, explicaram a importância da força para a realização das modalidades de voo. Uma luta de forças entre o vento e o piloto. Para vivenciarem a tensão entre forças opostas, propuseram um cabo de guerra entre dois grupos e explicaram que eles teriam que trabalhar a força, sempre ligando o conceito em relação ao vento e o equipamento. Após findar esta vivência, em roda, mostraram para as crianças o mapa que o Barão havia deixado para elas. 0 mapa as levou a encontrar uma caixa que continha materiais necessários para que cada criança construísse o seu mini parapente. Pouco a pouco e com o auxílio dos adultos, as crianças construíram e brincaram com os seus parapentes. Esta aula proporcionou a articulação de vivências corporais, reflexão sobre conceitos relacionados ao Voo e a produção de um brinquedo.

A quarta intervenção começou no parque após a recepção das crianças. As crianças chegaram e queriam brincar, porém a professora as chamou e organizou o grupo. Apresentamos o tema da aula que foi "a força do vento e a resistência que temos que fazer e o quanto isso afeta o equipamento e também a posição de voo", que é diferente no Parapente e na Asa Delta. O Barão retornou à aula com umas pipas para eles experimentarem a força e direção do vento. Depois de receberem as pipas, eles foram chamados para experimentar os equipamentos de segurança enquanto, deitados em um colchonete, deslizavam sobre o slackline. Esta estratégia facilitou a participação de todos haja vista que não necessitou de tempo de espera. Então com todos reunidos explicamos sobre a força do vento e perguntamos se conseguiam sentir isso com as pipas. Alguns falaram que sim, outros estavam dispersos e não prestaram atenção. Seguimos com a explicação e falamos que na próxima atividade um colega seria o vento e outro a resistência. Separamos as crianças em duplas e começamos a atividade. Formamos uma grande roda. Explicamos a relação do vento e demos um sentido para brincadeira. Explicamos que na Asa Delta quando apontada para cima ela perde velocidade e quando apontada para baixo ela ganha velocidade. Então quando a estagiária se abaixava a roda ganhava velocidade e quando levantava a roda diminuía. E também trocava de direção da roda. No fim da aula, com a ajuda dos professores, reunimos as crianças e dialogamos sobre a aula buscando relacionar com o voo livre e o tema proposto: força do vento e resistência.

Discutimos a importância de programar a próxima aula com antecedência, pois seria um fechamento com a turma e que consistiria em muitas atividades que precisávamos organizar. Para esta aula contamos com uma participação pontual de um assistente técnico em educação que é formado em EF e que voa de asa delta. ${ }^{3} \mathrm{O}$ mesmo se disponibilizou para trazer seu equipamento, montar e explicar sua estrutura, sobre seu manejo e segurança para as crianças. $O$ professor de EF também se mostrou disponível para nos ajudar e adaptar nossos planos de aula, assim como a professora de sala que nos atendia e auxiliava dentro do possível.

A última intervenção veio com muita expectativa de nossa parte, pois queríamos realizar um fechamento positivo para as crianças, - clima ajudou e conseguimos realizar esse encontro fora da instituição, em uma área verde na universidade. Convidamos as crianças para um 'Festival de Voo', em que conheceriam uma asa delta montada e os respectivos equipamentos e conversariam com um praticante desta modalidade. Também colocamos o slackline de uma forma segura para eles brincarem de forma mais autônoma. Disponibilizamos, também, os parapentes, as pipas e uma lona para brincarem de paraquedas. Decoramos o local com tecidos coloridos, mas as crianças trouxeram uma ressignificação e brincaram com eles também. Quando chegamos ao local e as crianças viram a asa delta e o ambiente decorado, elas se agitaram e saíram correndo em direção ao equipamento. Dentre as falas destacamos a de um menino: - meu Deus, meu Deus o que é isso?

\footnotetext{
${ }^{3}$ Este profissional atuou como responsável pela Educação Física nesta unidade por mais de 20 anos. Suas experiências influenciaram o trabalho do professor recém contratado, bem como a realização deste estágio.
} 
Olha isso! E a de uma menina que disse: - "É uma Asa Delta de verdade!"

Foto 1. Vivência com a asa delta

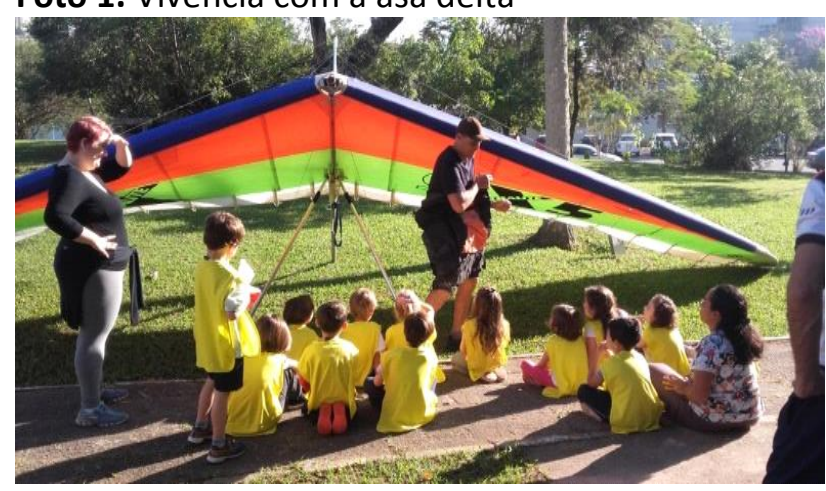

Fonte: Aulas de Educação Física (2019).

Então, reunimos todos perto da Asa, para ouvir o experiente esportista explicar sobre o equipamento e a prática do voo. Ele perguntou para as crianças se elas sabiam de quem era a asa delta. Uns falaram que era dele, mas outros associaram ao Barão. Ele disse que o Barão a deixou ali e que como voava, explicaria as suas partes, tiraria suas dúvidas e depois eles experimentariam e tirariam fotos na asa delta.

As crianças em geral escutaram com atenção e fizeram perguntas do tipo: É pesada? Você voa sempre? Onde você voa? Posso voar também? Aproveitamos a oportunidade para conversar sobre condições climáticas propícias para o voo e sobre os equipamentos. Foi interessante perceber as relações que as crianças conseguiram fazer: "hoje o tempo está bom", "o vento está forte", "é preciso usar o capacete", "mas aqui não é alto, como vai saltar?". Durante o momento de tirarem as fotos e experimentarem o contato com a asa, combinamos coletivamente que quem estivesse esperando, sua vez, poderia brincar no slackline e com os outros brinquedos disponíveis.

Logo depois, os levamos de volta para a escola, no horário do lanche. Recolhemos os materiais do local e fomos ajeitar o auditório onde iria acontecer o final da aula. Chegando lá, cada uma sentou em uma cadeira e explicamos que como era nossa última intervenção iríamos mostrar as fotos de todas as nossas aulas. Quando falamos que era a última aula as crianças exclamaram: "Ahh, Ah não!" Então mostramos as fotos, e elas ficaram atentas e reconheceram a si mesmas e os colegas nas imagens. Perguntamos também enquanto passavam as fotos o que eles lembravam e percebemos que os principais conceitos foram recordados: "isso é parapente e isso é asa delta!", "olha o motor do parapente", "a asa delta é maior", "os dois têm equipamentos de segurança". Eles explicaram aspectos das aulas e identificam as diferenças entre parapente, asa delta, relacionadas ao vento e força.

\section{CONSIDERAÇÕES FINAIS}

O texto que apresentamos, relata nossa experiência de ensino em meio ao estágio obrigatório em Educação Física com o conteúdo voo livre na Educação Infantil. De modo geral, foi um processo desafiador, porém muito enriquecedor para todos os envolvidos, professor e estagiários em processo de formação inicial. Fomos levados a conhecer a instituição e a turma, a planejar com cuidado teórico e didático e avaliar o envolvimento das crianças com o conteúdo apresentado. Por vezes, chegamos a considerar as modalidades de voo livre inapropriadas para a Educação Infantil e para os desafios próprios que se colocam ao G6. Também consideramos a inexistência de relatos de ensino sobre este conteúdo no âmbito da EF escolar, o que nos impôs o desafio de criação muito maior.

Porém, ao longo de nossa imersão na instituição, tivemos a orientação de outros profissionais que auxiliaram em todo o trabalho ali desenvolvido fazendo com que, aos poucos, o conteúdo tomasse forma adequada ao público destinatário demonstrando, assim, sua relevância e contribuição com o objetivo da professora que abordou o livro sobre as aventuras do Barão de Munchausen.

Também vimos que teríamos que trazer mais elementos lúdicos e que chamassem mais a atenção das crianças, nosso planejamento inicial estava muito focado numa prática e pouco adaptado às especificidades das crianças. Mas isso foi mudando e se construindo no decorrer das intervenções com a ajuda dos supervisores e da professora de sala. Outro fator que facilitou o processo refere-se ao fato da instituição estar aberta e disponível a nos ajudar com materiais e local para as propostas.

Refletindo a nossa abordagem teóricometodológica frente ao processo pedagógico realizado, acreditamos que conseguimos adequar o ensino de uma PCAN pouco comum na educação infantil. Destacamos também que alguns aspectos importantes que elegemos como objetivos foram plenamente ou parcialmente cumpridos. Conseguimos evidenciar certas diferenças entre os tipos de voo e esclarecer a 
importância das normas de segurança, das regras e de cuidados consigo e com os colegas. Tivemos um pouco mais de dificuldade para lidar com situações de medo de altura, tema da maior importância e que exige uma discussão mais aprofundada sobre as emoções na primeira infância, como se constituem e as possibilidades de superação. Esta questão ainda pode ser aprofundada em experiências futuras. A questão dos riscos e perigos inerentes a esta PCAN, surgiu numa das conversas com as crianças.

Tivemos certa dificuldade e evitamos o tema do risco de morte, que em nossa avaliação merecia melhor fundamento. Tivemos dificuldades para planejar e encaminhar as conversas finais de cada aula, devido a pouca experiência da equipe de estagiárias em problematizar as vivências das crianças, de mediar processos de reflexão sobre as aulas e de proporcionar um ambiente mais favorável para que todas participassem. Uma parte desta dificuldade se deve as situações de conflitos e perturbações frequentemente protagonizadas pelos dois "alunos especiais" da turma. Estes casos ultrapassaram nossas competências e exigiram a intervenção coletiva dos profissionais da instituição. Tivemos grandes dificuldades para incluí-los nas aulas. Em uma de nossas conversas com a professora ela deixou claro que esses casos também são um desafio para a mesma e que há casos que fogem de nosso alcance.

Porém, sabemos que as crianças têm seu tempo próprio e que nossas aulas, por vezes, eram de longa duração, desinteressantes ou pouco adaptadas a sua realidade, mesmo assim exigindo concentração. Este controle de suas energias exigia, de nossa parte, uma mediação e propostas de atividades mais calmas. Não conseguimos efetivamente fazer reflexões sobre os temas da sustentabilidade ou relacionados à ecologia, para dar prioridade ao tema da segurança das mesmas sobre a prática e o cuidado com seus colegas.

Por fim, este trabalho propõe a reflexão sobre a importância de nós professores de Educação Física pensarmos que questões como agressividade, medo, inclusão e os impactos nas vivências com as crianças e o papel do professor mediar na direção da superação destas situações. Mostra a importância da Educação Física na Educação Infantil e sua contribuição na abordagem de temas transversais $e$ interdisciplinares. Refletimos, inclusive, sobre a especificidade da Educação Física na primeira etapa da Educação Básica, tema que vem ganhando fôlego vista a produção de trabalhos acadêmicos que tematizam as crianças, o movimento, o corpo, constitui-se em lugar privilegiado do aprender, das relações e de uma formação humana voltada à cidadania, saúde e consciência crítica sobre o mundo onde vivemos.

É importante destacar a importância desta relação de proximidade entre universidade e Educação Básica, a forma profissional e engajada como a equipe local acolheu o estágio de forma completa, com disposição para mostrar os limites e auxiliar nos processos de formação.

Ao darem início ao estágio, as estagiárias não tinham muita clareza sobre querer ser professora, porém também tinham pouca ou nenhuma experiência no ensino da Educação Infantil. Uma delas dizia não querer trabalhar com a Educação Infantil. Havia muito medo, incerteza, pois no curso de licenciatura há pouco espaço para se refletir ou estudar sobre a infância. No final, o medo, as incertezas e angústias, se transformaram, e deram lugar a uma segurança: "eu posso dar aula para essas crianças e que elas também têm muito a nos ensinar e que me deram muitos elementos para refletir e me ajudar na minha formação como professora. Terminei esse estágio com uma alegria e também com saudades, pois ele me modificou, tanto na minha formação profissional e pessoal também." Esta foi uma oportunidade singular para se construir, desconstruir e reconstruir conhecimentos obtidos nas aulas teórico-metodológicas ao longo de nossa formação inicial.

Pudemos compreender que as crianças são seres humanos com menos idade, mas já com suas experiências, suas histórias e devemos respeitar as mesmas e principalmente aprender que cada uma tem seu tempo, sua personalidade. Muitas vezes focamos o olhar no que não deu certo, que uma atividade não durou o tanto quanto nos dedicamos a planejar, mas percebemos que não é isso que conta, mas sim: o que deixamos para elas com todas estas experiências. A felicidade com que elas se envolveram no momento ou a superação de um medo, vale muito mais. Aprendemos que o processo é muito mais enriquecedor, o que importa é o caminho percorrido.

\section{REFERÊNCIAS}

BRASIL. MINISTÉRIO DA EDUCAÇÃO. Base Nacional Comum Curricular, 2018. Disponível 
em: <http://basenacionalcomum.mec.gov.br/>. Acesso em: 07 maio 2019.

DIAS, C. A. G.; ALVES J.; DRUMOND E. de (Orgs.). Em busca da aventura: múltiplos olhares sobre esporte, lazer e natureza. Rio de Janeiro: Editora da UFF, 2009.

FLORIANÓPOLIS. Prefeitura de Florianópolis. Prefeitura de Florianópolis (Org.). Proposta Curricular do Município de Florianópolis. 2016. Disponível em: http://www.pmf.sc.gov.br/entidades/educa/inde x.php?cms=proposta+curricular \&menu=10\&sub menuid=253. Acesso em: 27 jun. 2019.

KOCK, F. Guia de Ecoturismo e Esportes de Aventura de Floripa. Florianópolis: Trames, 2007.

SOARES, C. L. et al. Metodologia do Ensino de Educação Física. São Paulo: Cortez, 1992.

SANTA CATARINA. Grupo Gestor do Núcleo de Desenvolvimento Infantil. Universidade Federal de Santa Catarina (Org.). Proposta Curricular. $2014 . \quad$ Disponível em: <http://ndi.ufsc.br/files/2015/04/PropostaCrricular-do-NDI.pdf>. Acesso em: 07 maio 2019

PAIXÃO J. A. da. Esporte de aventura como conteúdo possível nas aulas de Educação Física escolar. Motrivivência v. 29, n. 50, p. 170-182, maio/2017. Disponível em: https://periodicos.ufsc.br/index.php/motrivivenci a/article/view/2175-8042.2017v29n50p170.

Acesso em: 03 de março de 2019. https://doi.org/10.5007/2175$\underline{8042.2017 v 29 n 50 p 170}$

PEREIRA, D. W.; ARMBRUST, I. Pedagogia da aventura: os esportes radicais, de aventura $e$ de ação na escola. São Paulo: Fontoura, 2010.

PROPOSTA CURRICULAR NDI. Universidade federal de Santa Catarina, 2014.

VAZ, A. F.; SAYÃO, D. e PINTO, F. M. Educação do corpo e formação de professores: reflexões sobre a prática de ensino de Educação Física. Florianópolis: EDUFSC, 2002. 